\title{
Article
}

\section{The effect of temperature and ventilation condition on the toxic product yields from burning polymers}

Stec, Anna A, Hull, T Richard, Lebek, K., Purser, J. A. and Purser, D. A.

Available at http://clok.uclan.ac.uk/1091/

Stec, Anna A ORCID: 0000-0002-6861-0468, Hull, T Richard ORCID: 00000002-7970-4208, Lebek, K., Purser, J. A. and Purser, D. A. (2008) The effect of temperature and ventilation condition on the toxic product yields from burning polymers. Fire and Materials, 32 (1). pp. 49-60. ISSN 03080501

It is advisable to refer to the publisher's version if you intend to cite from the work. http://dx.doi.org/10.1002/fam.955

For more information about UCLan's research in this area go to http://www.uclan.ac.uk/researchgroups/ and search for <name of research Group>.

For information about Research generally at UCLan please go to http://www.uclan.ac.uk/research/

All outputs in CLoK are protected by Intellectual Property Rights law, including Copyright law. Copyright, IPR and Moral Rights for the works on this site are retained by the individual authors and/or other copyright owners. Terms and conditions for use of this material are defined in the policies page.

\section{CLoK}

Central Lancashire online Knowledge www.clok.uclan.ac.uk

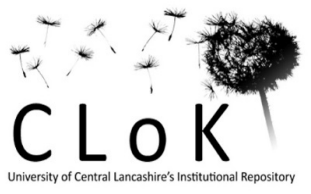




\title{
The Effect of Temperature and Ventilation Condition on the Toxic Product Yields from Burning Polymers
}

\author{
A.A.Stec, T.R.Hull, K.Lebek, J.A.Purser, D. A. Purser \\ Fire Materials Laboratory, CMRI, University of Bolton, Deane Road, Bolton, BL3 5AB, UK
}

\begin{abstract}
A major cause of death or permanent injury in fires is inhalation of toxic gases. Moreover, every fire is unique, and the range of products, highly dependant on fire conditions, produces a wide variety of toxic and irritant species responsible for the most fire fatalities. Therefore, to fully understand each contribution to the toxicity it is necessary to quantify the decomposition products of the material under the test.

Fires can be divided into a number of stages from smouldering combustion to early wellventilated flaming, through to fully developed under-ventilated flaming. These stages can be replicated by certain bench-scale physical fire models using different fuel-to-oxygen ratios, controlled by the primary air flow, and expressed in terms of the equivalence ratio (the actual fuel/air ratio divided by the stoichiometric fuel/air ratio).

This work presents combustion product yields generated using a small-scale fire model. The Purser Furnace apparatus (BS7990 and ISO TS 19700) enables different fire stages to be created. Identification and quantification of combustion gases and particularly their toxic components from different fire scenarios was undertaken by continuous Fourier Transform Infrared Spectroscopy. The relationship between type of the fire particularly the temperature and ventilation conditions, and the toxic product yields for four bulk polymers, LDPE, PS, Nylon 6.6 and PVC are reported.

For all the polymers tested, except PVC, there is a dramatic increase in the yield of products of incomplete combustion ( $\mathrm{CO}$ and hydrocarbons) with increase in equivalence ratio, as might be expected. For PVC there is a consistently high level of products of incomplete combustion arising both from flame inhibition by $\mathrm{HCl}$, and oxygen depletion. There is a low sensitivity to furnace temperature over the range $650-850^{\circ} \mathrm{C}$, except that at $650^{\circ} \mathrm{C}$ PS shows an unexpectedly high yield of CO under well-ventilated conditions and PVC shows a slightly higher hydrocarbon yield. This demonstrates the dependence of toxic product yields on the equivalence ratio, and the lack of dependence on furnace temperature, within this range.
\end{abstract}




\section{INTRODUCTION}

Inhalation of toxic gases is a major cause of death or permanent injury in fires. To fully understand the causes of this toxicity it is necessary to understand burning behaviour of the material under test. In all fires, combustion is maintained by the reaction of oxygen in the air with combustible gases produced from the thermal decomposition of materials. Gases generated from burning materials comprise complex mixtures of fully oxidised products, such as carbon dioxide $\left(\mathrm{CO}_{2}\right)$, partially oxidised products, such as carbon monoxide (CO) or aldehydes, fuel or fuel degradation products, such as aliphatic or aromatic hydrocarbons, and other stable gas molecules, such as nitrogen and hydrogen halides. ${ }^{1}$

Research suggests that the major toxic effects on humans are caused by a few common gases generated during the combustion process, and of these carbon monoxide is often considered to be the main factor influencing the hazard to human life from fire by preventing oxygen transport by the formation of carboxyhaemoglobin. $^{2}$ The ease of detection of carboxyhaemoglobin in fire victims, or laboratory animals, is the probable reason for attributing so many fire deaths solely to $\mathrm{CO}$. However, $\mathrm{CO}$ is also as an indicator of fire conditions showing higher yields during smouldering and underventilated combustion.

Mixtures of many different gases obtained during combustion depend not only on the material being burned but also on the conditions of burning. As the fire develops, the conditions change: the temperature increases and oxygen concentration decreases, resulting in different concentrations of combustion products. This work presents the relationship between the ventilation conditions and product yields at different temperatures. Combustion products are generated using the steady state tube furnace (Purser Furnace BS 7990 and ISO TS 19700), a small-scale apparatus 
enabling an estimate of toxic product yields at each different fire stage to be made, using on-line Fourier Transform Infrared Spectroscopy (FTIR) for identification and quantification of the products.

Another bench-scale apparatus, the Factory Mutual ASTM E2058 fire propagation apparatus also enables the relationship between product yields and ventilation conditions to be measured, but the form of the apparatus and method of sample exposure differ considerably from that in the BS 7990 apparatus. ${ }^{4}$ Despite these differences Purser ${ }^{5}$ found a good agreement between the CO yields obtained from the two methods for three polymers (low density polyethylene, polymethylmethacrylate and polystyrene) when expressed in terms of the ratio of yields obtained at different fuel air equivalence ratios as a function of the yields obtained under well-ventilated combustion conditions. In this paper BS7990 tube furnace yields for a different combustion products obtained from more polymers over a wider range of temperatures and equivalence ratios are presented and compared with yields calculated from calculation formulas derived by Tewarson using the ASTM E2058 apparatus.

\section{Setting up fire stages}

Fires can be divided into a number of stages, from smouldering combustion and early well-ventilated flaming, through to fully developed under-ventilated flaming. ${ }^{3}$ Those flaming stages are critically dependent on the fuel-to-oxygen ratios, controlled by the air supply. ${ }^{6,10}$ This can be expressed in terms of the equivalence ratio, $\phi$, shown in Equation 1.

$$
\phi=\frac{\text { Actual fuel / Air ratio }}{\text { Stoichiometric fuel / Air ratio }} \text { Equation } 1
$$




$$
\begin{aligned}
\phi & =1 \text { “stoichiometric" combustion } \\
\phi & <<1 \text { well-ventilated fires (fuel lean flames) } \\
\phi & >1 \text { vitiated fires (fuel rich flames) }
\end{aligned}
$$

If the amount of oxygen equals the oxygen requirement of the fuel, then the conditions are said to be stoichiometric and the equivalence ratio equals 1 . If the equivalence ratio is higher, then there is less than the stoichiometric amount of the air and the conditions are vitiated, and if the air requirement is exceeded then the conditions are well-ventilated. ${ }^{7}$ Since, it is well established that the yield of at least two major toxicants $\mathrm{CO}$ and $\mathrm{HCN}$ are critically dependent on the degree of ventilation, it is therefore vital that for meaningful toxic product yields to be obtained from a bench-scale method the fuel/oxygen ratio must be known. ${ }^{8}$ A simplified classification of fire stages with temperature is presented in Table 1.

\begin{tabular}{|l|c|c|}
\hline & $\begin{array}{c}\text { Temperature } \\
\left({ }^{\circ} \mathbf{C}\right)\end{array}$ & Equivalence ratio \\
\hline Smouldering & 350 & not applicable \\
\hline Well-ventilated flaming & 650 & $\phi<0.75$ \\
\hline Less well-ventilated flaming: & & \\
$\bullet \quad$ small vitiated fires & 650 & $\phi>1.5$ \\
post-flashover fires & 825 & $\phi>1.5$ \\
\hline
\end{tabular}

Table 1 Classification of the fire stages

The aim of this study was to investigate the influence of the equivalence ratio, temperature and material composition on the yields of toxic combustion gases. 


\section{EXPERIMENTAL}

\section{Apparatus}

The Purser Furnace, Figure 1, is a small-scale physical fire model designed to create the fire conditions occurring in different stages of fire, in order to better understand thermal decomposition and particularly combustion toxicity of plastic products. ${ }^{9}$

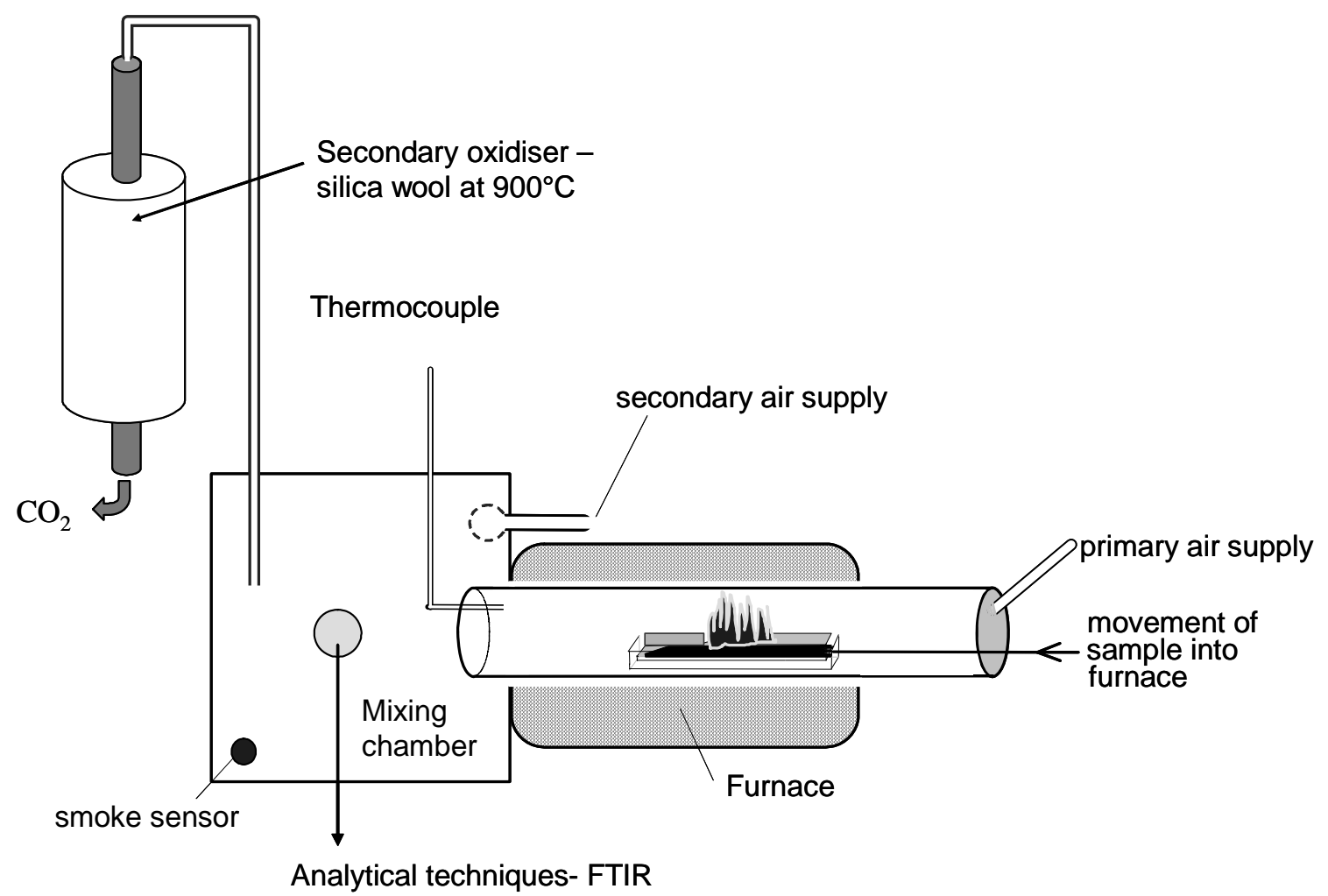

Figure 1 Purser Furnace

The apparatus consists of a static tube furnace in which a quartz tube is fixed. A uniform length of test specimen is placed along the length $(\sim 80 \mathrm{~cm})$ of a silica boat. During an experiment, the sample is pushed into the furnace tube, at a constant rate, by a drive mechanism. A fixed stream of primary air passes through the tube furnace into a mixing and measuring chamber where it is diluted with a fixed and controlled 
secondary air supply. Primary air passing over the specimen supports the combustion process. Secondary air increases the volume of analyte, and tends to keep the effluents from different ventilation conditions within the same analytical range.

Gas samples for analysis are taken directly from the Purser furnace mixing chamber, Figure 2, and then drawn continuously through heated lines and filters, by a pump, to a heated, folded path length gas cell of an FTIR spectrometer. From the absorption spectra, the chemical species present in the fire gases, generated by the various polymers under different fire conditions, can be continuously identified and quantified.

Hydrocarbon yields were determined from the difference in $\mathrm{CO}_{2}$ yield between the mixing chamber and secondary oxidiser effluent, since any unburned or partially burnt hydrocarbons would be oxidised to $\mathrm{CO}_{2}$ at $900^{\circ} \mathrm{C}$ in the presence of excess of oxygen. The hydrocarbon yields are expressed in grams of $\mathrm{CH}_{2}$ per gram of polymer.

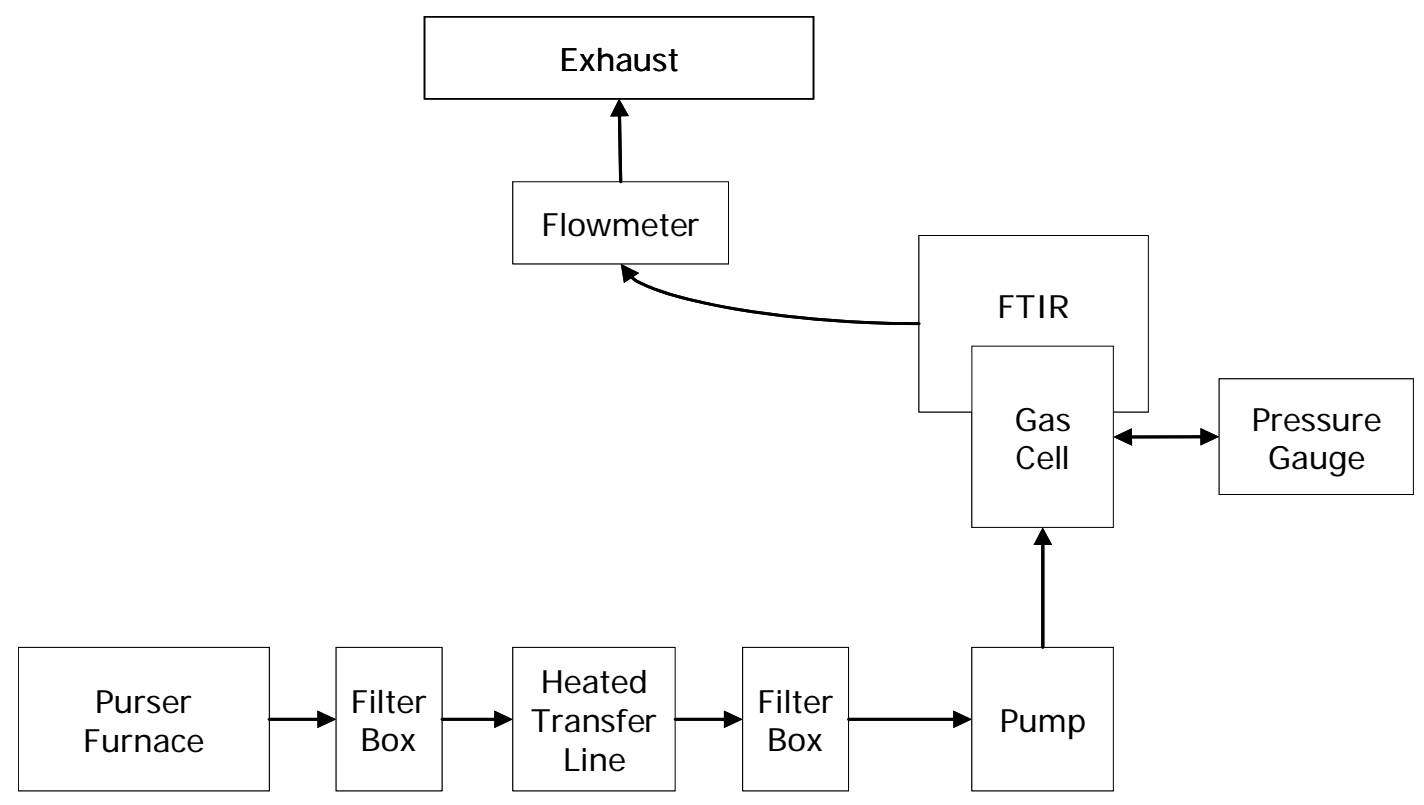

Figure 2 Schematic layout for the gas flow 
The spectra of the decomposition and combustion products of the material were collected using a standard FTIR equipped with a DTGS detector at $4 \mathrm{~cm}^{-1}$ resolution and scanning time of 10 seconds. The gas cell, the heated lines and filters were heated to $150^{\circ} \mathrm{C}$. The gases were sampled continuously at a controlled flow rate of 4 litres per minute and a pressure of 1.050 bar.

Figure 3 shows the behaviour of the tube furnace moving quickly through the different stages of the fire, ignition and growth in order to achieve a period of steady state burning at the desired fire condition. The yields for each fire condition are taken minimum of 5 minute steady state period.

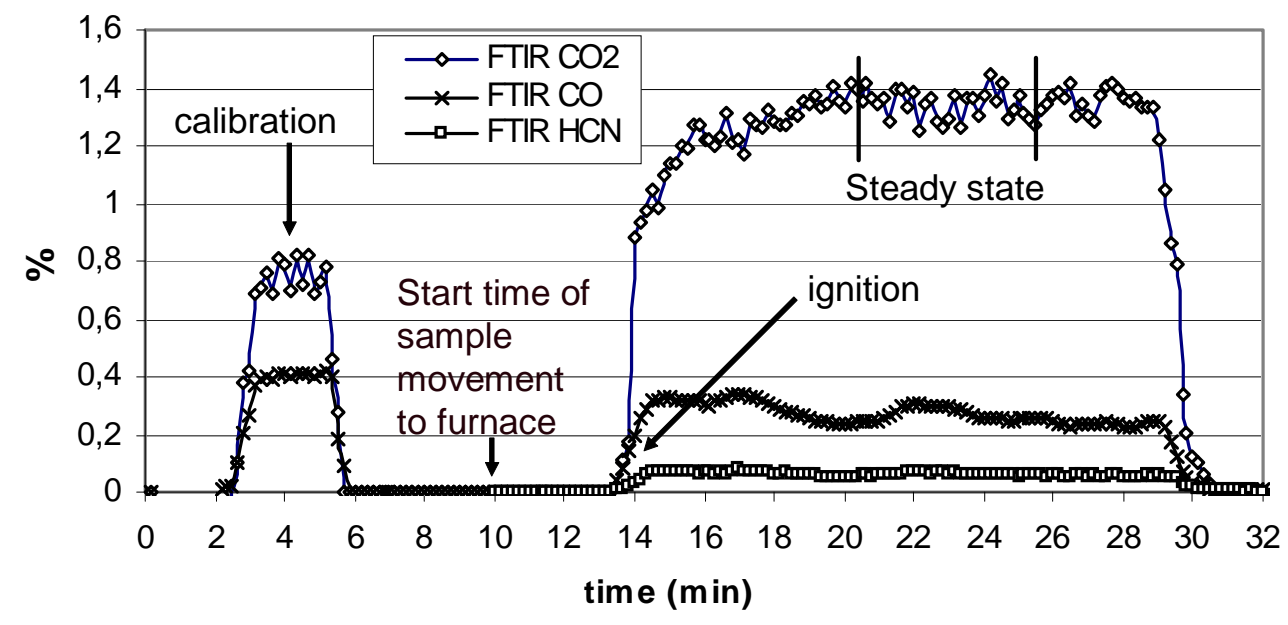

Figure 3 Steady state in the Purser Furnace (PA 6.6 in this example)

\section{Materials}

The materials were selected to provide a range of different toxic products, showing different yield behaviour as a function of equivalence ratio and furnace temperature. It has already been established that the yields of $\mathrm{CO}$ from a number of CHO containing non-aromatic polymers is independent of the actual polymer 
structure. ${ }^{10}$ This work sought to see how far that concept could be extended. The use of FTIR analysis allowed a greater range of combustion products to be analysed from different materials, and was carried out under different fire conditions, of ventilation and temperature, to investigate the sensitivity to each. These conditions were adjusted to range from well-ventilated to under-ventilated conditions.

Polyvinyl chloride (PVC), low density polyethylene (LDPE), polystyrene (PS), and Nylon 6.6 (PA 6.6) were obtained as commercial grade materials from Northern Industrial Plastics, all supplied as 2-4 mm pellets.

\section{Fire Conditions}

The experiments were carried out at three different furnace temperatures, $650^{\circ} \mathrm{C}, 750^{\circ} \mathrm{C}$, and $850^{\circ} \mathrm{C}$, except for LDPE, where the tests were carried out at two temperatures: $650^{\circ} \mathrm{C}$ and $850^{\circ} \mathrm{C}$. At each furnace temperature different primary air flows were used to change the ventilation condition. These are reported in terms of the equivalence ratio $\phi$.

\section{RESULTS AND DISCUSSION}

FTIR

Interpretation of the infrared spectrum is based on the intensity of absorption at particular frequencies. However for the small molecules found in fire gases, each molecule will contribute its absorption to the composite spectrum, independent of the other species present. In general, all the absorptions quoted fall within the range 4000$400 \mathrm{~cm}^{1}$. The major components of fire gas, $\mathrm{CO}_{2}, \mathrm{H}_{2} \mathrm{O}$ and $\mathrm{CO}$ will be observed for 
practically all organic materials. Hydrogen chloride ( $\mathrm{HCl})$ is only observed for PVC and hydrogen cyanide (HCN) for Nylon 6.6. Individual absorption spectra of the calibration gases detected by FTIR are presented in Figure 4.

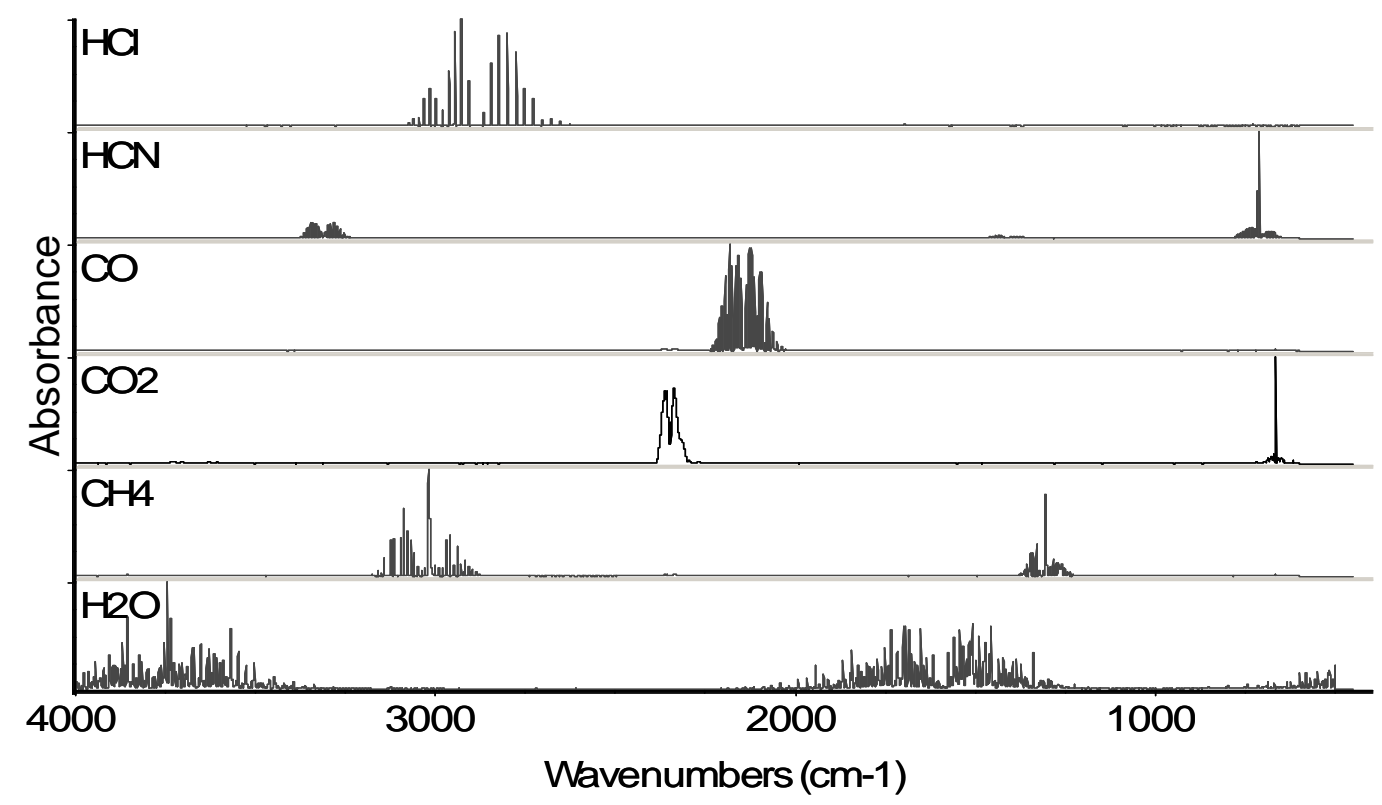

Figure 4 Combustion products detected by FTIR

\section{Toxic Product Yield}

During a fire, the majority of materials generate effluents whose nature and concentration presents a toxicity hazard for people. The toxicity of a fire effluent can be predicted from the yield of toxic products and smoke in the fire. In general, the yields of these species are strongly dependent upon the material, decomposition and ventilation conditions. ${ }^{11}$ The yields of $\mathrm{CO}$, hydrocarbon, and where appropriate, $\mathrm{HCl}$ and HCN, under different fire conditions defined by the equivalence ratio and temperature, are presented below.

\section{Low Density Polyethylene (LDPE)}


LDPE was burned at different furnace temperatures $\left(650^{\circ} \mathrm{C}\right.$ and $\left.850^{\circ} \mathrm{C}\right)$ giving relatively low carbon monoxide yields under well-ventilated conditions $(\phi<<1)$. As the equivalence ratio increases, the carbon monoxide yields increase, reaching a plateau around $\phi=1.3$. (Figure 5) and the hydrocarbon yields increase without reaching a plateau when $\phi>2.0$. (Figure 6)

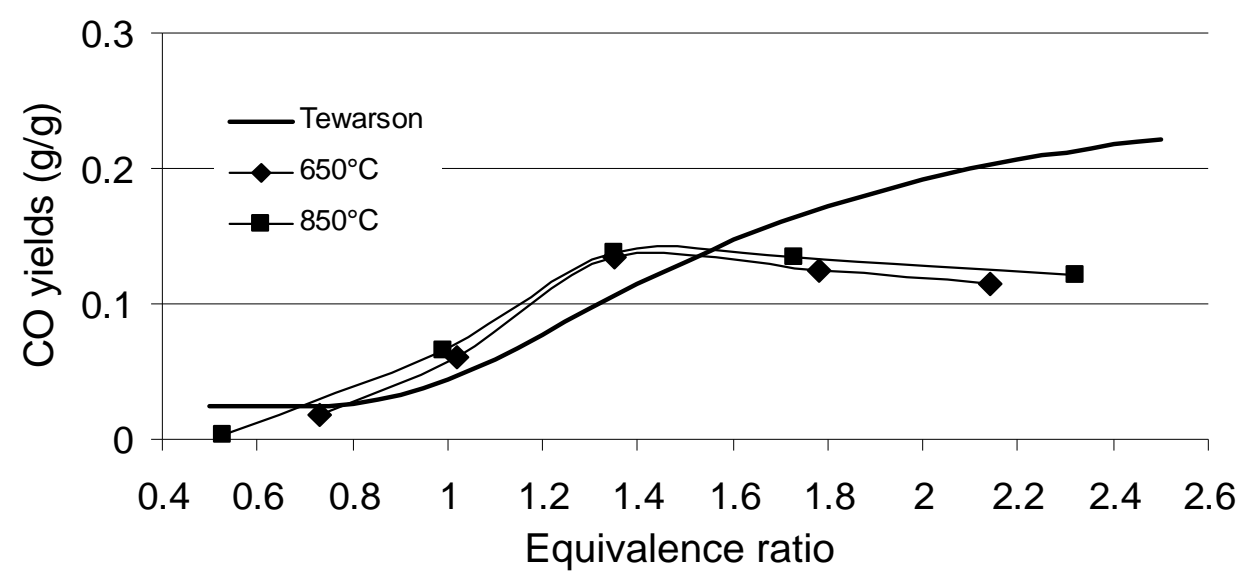

Figure 5 LDPE carbon monoxide yields

The results show that the $\mathrm{CO}$ yields is independent of the furnace temperature for LDPE over the range studied. Tewarson has presented formulae for prediction of toxic product yields as a function of equivalence ratio. The predicted yields of $\mathrm{CO}$ and hydrocarbons for LDPE have been plotted alongside the data reported here. Comparable results are observed for CO (Figure 5) and hydrocarbon (Figure 6) yields by Tewarson, using the fire propagation apparatus (ASTM E2058) (FPA), which show broad agreement. ${ }^{4,12}$ Furthermore, hydrocarbons give similar correspondence at different temperatures and ventilation conditions, as presented in Figure 6. However, Tewarson's yield of both CO and hydrocarbons continue to increase with increasing $\phi$, reaching a higher plateau, suggesting less complete mixing, or quenching of the fire gases at under-ventilated conditions in the FPA. 


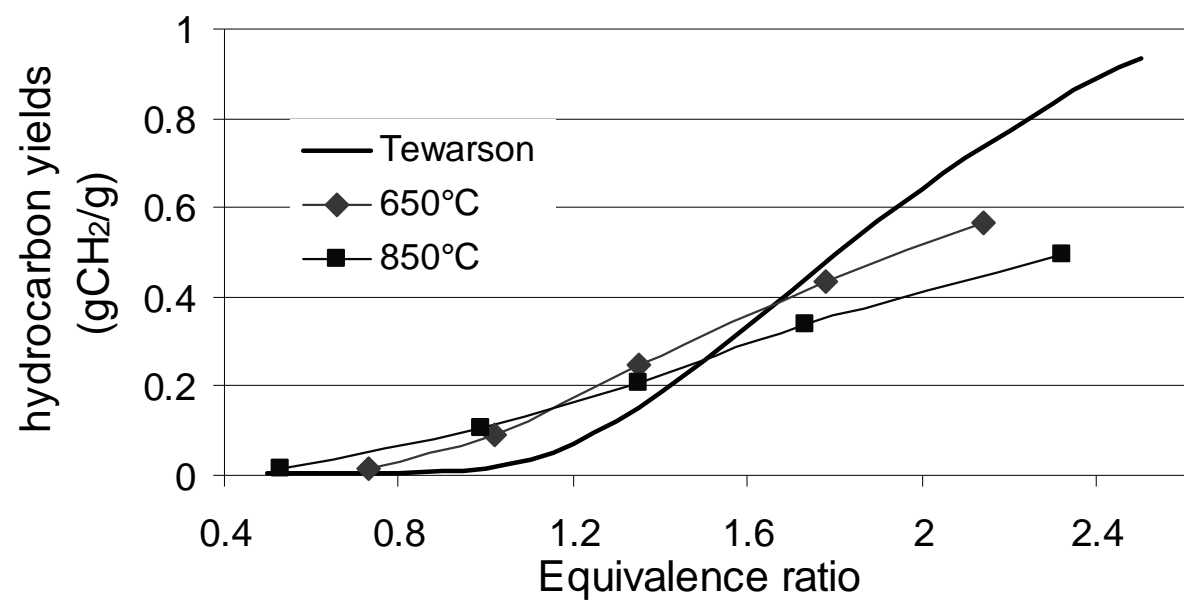

Figure 6 LDPE hydrocarbon yields

\section{$\underline{\text { Polystyrene (PS) }}$}

The carbon monoxide yields from PS under different fire conditions are presented in Figure 7. In all tests, within the temperature range investigated, the CO yield increases as the equivalence ratio increases.

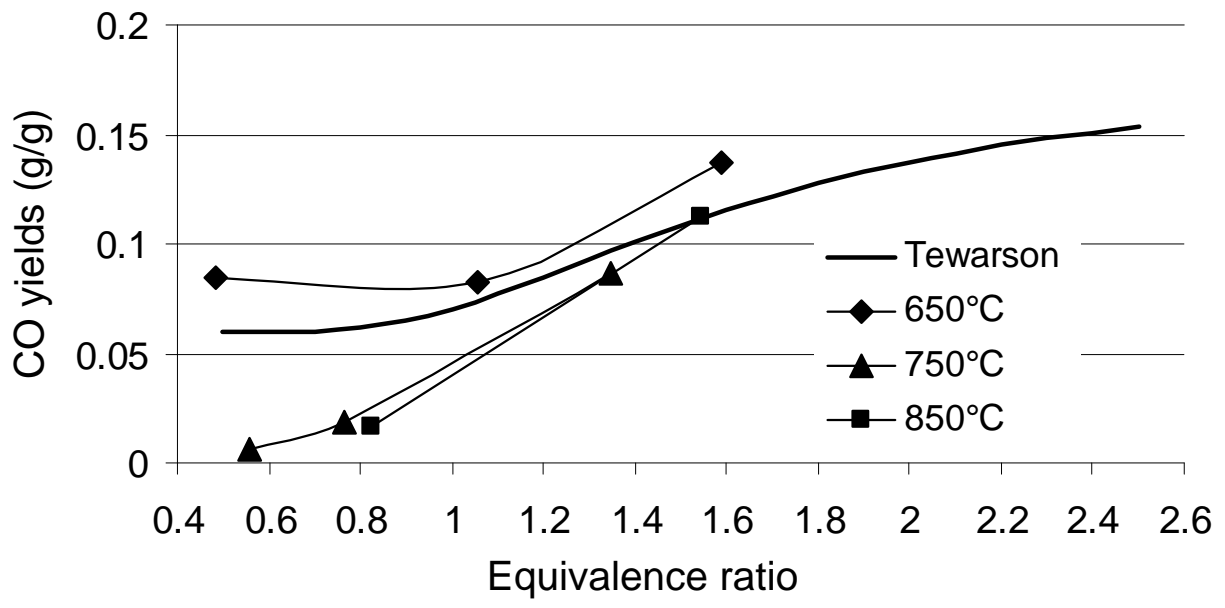

Figure 7 PS carbon monoxide yields

However, there is a noticeable increase in the $\mathrm{CO}$ yield at $650^{\circ} \mathrm{C}$ under well ventilated conditions. This has been observed elsewhere ${ }^{10}$ and is attributed to the enhanced stability of the aromatic fuel molecules, which are incompletely oxidised in 
the flame zone at a furnace temperature of $650^{\circ} \mathrm{C}$, but much more completely oxidised at $750^{\circ} \mathrm{C}$ and $850^{\circ} \mathrm{C} .^{13}$

Low sensitivity to furnace temperature and increase in yield with decrease in ventilation is observed for hydrocarbons from PS, presented in Figure 8. In particular, this shows that despite the higher $\mathrm{CO}$ yields at $650^{\circ} \mathrm{C}$, under well-ventilated conditions, there is no corresponding increase in the hydrocarbon yield. In addition, there is very good agreement for hydrocarbon and CO yields with predictions reported by Tewarson from the fire propagation apparatus.

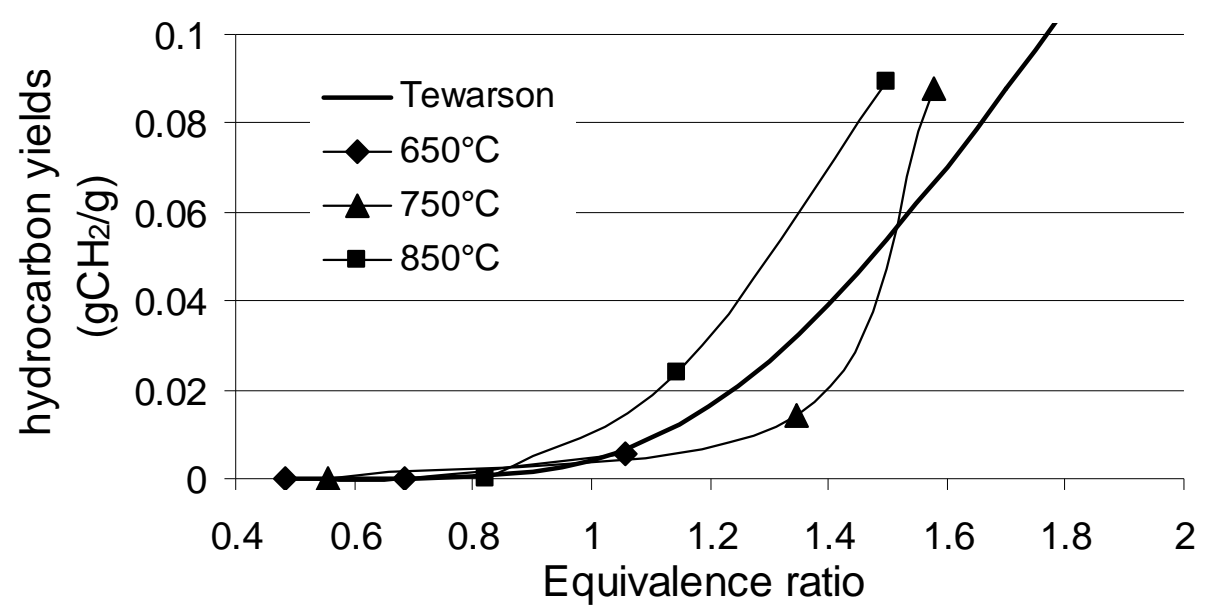

Figure 8 PS hydrocarbon yields

\section{$\underline{\text { Polyvinyl chloride (PVC) }}$}

The influence of ventilation conditions and furnace temperature on the fire effluent yields for PVC is shown in Figure 9.

It can be stated that CO yields in the steady state tube furnace are almost constant with increase in $\phi$ at each temperature. At a temperature of $850^{\circ} \mathrm{C}$ this correlation seems to become weaker, suggesting more complete combustion under well-ventilated conditions. This implies that the flame quenching effect of $\mathrm{HCl}$, which 
inhibits the conversion of $\mathrm{CO}$ to $\mathrm{CO}_{2}$, the major heat release step of hydrocarbon combustion is less effective at higher temperatures. However, this observation is based on a single steady state run, further investigation is necessary before final conclusions can be drawn.

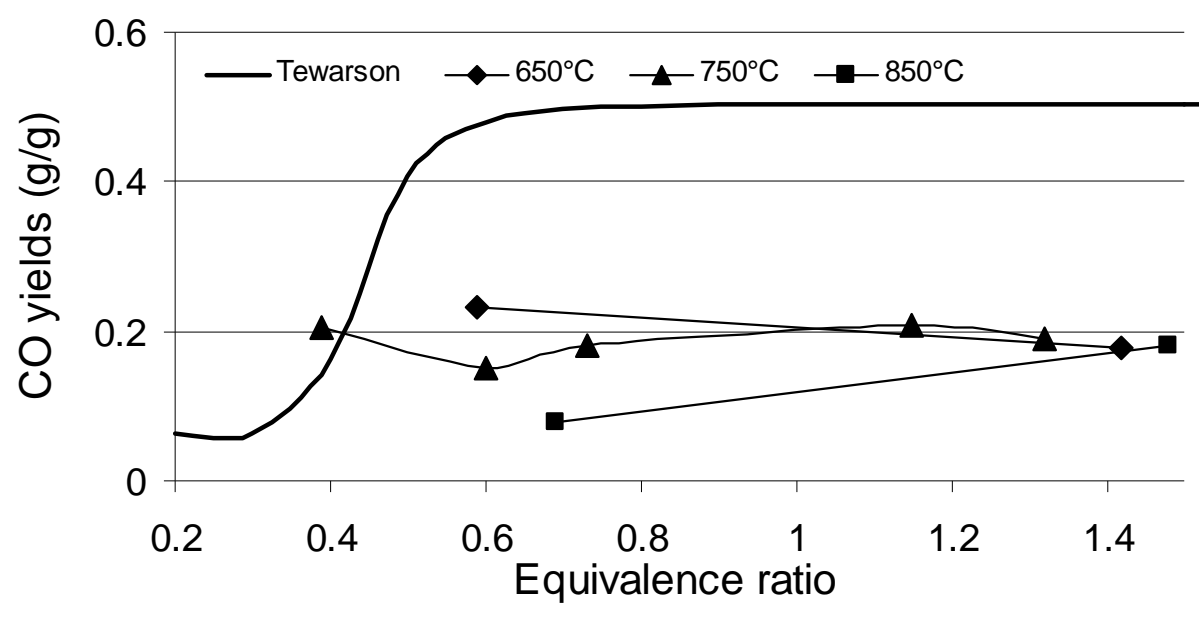

Figure 9 PVC carbon monoxide yields

The poor agreement with the Tewarson results, particularly for $\phi<0.6$ may be an artefact of the measurement method. The FPA sample, mounted on a load cell, is subjected to a fixed radiant flux in a vertical quartz tube. The equivalence ratio is determined from the mass loss, the air-flow through the tube, and the stoichiometric oxygen requirement of the sample. A full range of equivalence ratios can thus be obtained from a single experiment. Under well-ventilated conditions the CO yield was reported as $0.063 \mathrm{~g} / \mathrm{g}$, corresponding to early stages of mass loss, with little oxygen requirement, probably because most of the mass loss from the PVC was $\mathrm{HCl}$. It is not clear whether flaming had occurred at that stage. Another feature of the ASTM E2058 apparatus is that the sample is exposed in the form of a static disc of material. Therefore, once the $\mathrm{HCl}$ has been liberated from the sample during the early stages of heating and has flowed out of the apparatus, the vapour phase combustion of gases from the remaining char is no longer influenced by vapour phase free-radical 
scavenging. In contrast, the steady state tube furnace method ensures homogeneous sample decomposition, with some parts of the sample undergoing dehydrochlorination, while other parts consist of a decomposing char (similar to the condition in a full-scale spreading fire). This gives the somewhat surprising independence of CO yield to ventilation condition, and flaming is clearly visible. As the fire condition becomes less well-ventilated, when the equivalence ratio rises from 0.4 to 0.6 the FPA gives a higher yield of $\mathrm{CO}(0.47 \mathrm{~g} / \mathrm{g})$ than the steady-state tube furnace $(0.2 \mathrm{~g} / \mathrm{g})$. This is because the decomposing material now consists of char, which is carbon-rich compared to the original polymer. The principal differences between the two apparatuses, which both allow for good mixing of the primary air with the fire plume is that the FPA is a wider vertical tube, which will allow natural convection of the fire plume, with perhaps more CO around the middle of the tube, while the steady-state tube furnace uses a narrower tube, where the primary air will be drawn through the fire plume. Also, in the tube furnace the material is continually introduced in the form of a strip, while in the ASTM E2058 apparatus the material is in the form of a static plate.

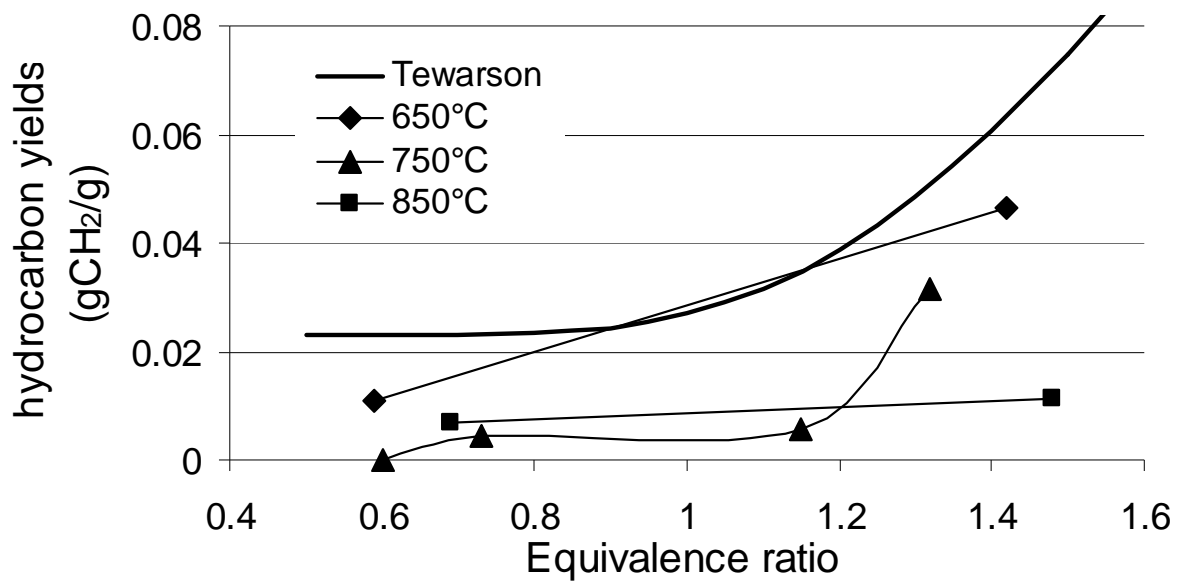

Figure 10 PVC hydrocarbon yields 
The results for PVC hydrocarbon yields are presented in Figure 10. This also suggests a diminution of the flame inhibiting effect of $\mathrm{HCl}$ with increase in temperature, though, as with polystyrene, the effect on hydrocarbon yields is different to that on $\mathrm{CO}$ yields.

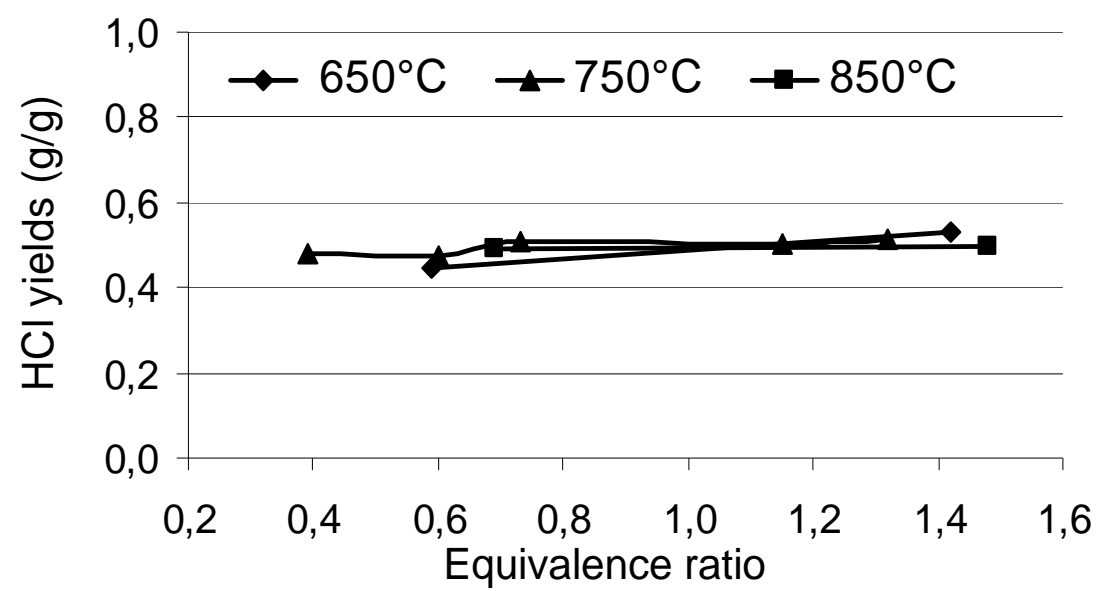

Figure 11 PVC HCl yields

The $\mathrm{HCl}$ yields, presented in Figure 11, are independent of both equivalence ratio and furnace temperature. This is not surprising, since $\mathrm{HCl}$ is lost from PVC between $190-250^{\circ} \mathrm{C}$.

\section{Nylon 6.6 (PA 6.6)}

Carbon monoxide and hydrogen cyanide yields were determined for series of characteristic fire stages for Nylon 6.6. Carbon monoxide yields at different fire scenarios, from well-ventilated to post-flashover, at three different furnace temperatures are presented below in Figure 12. 


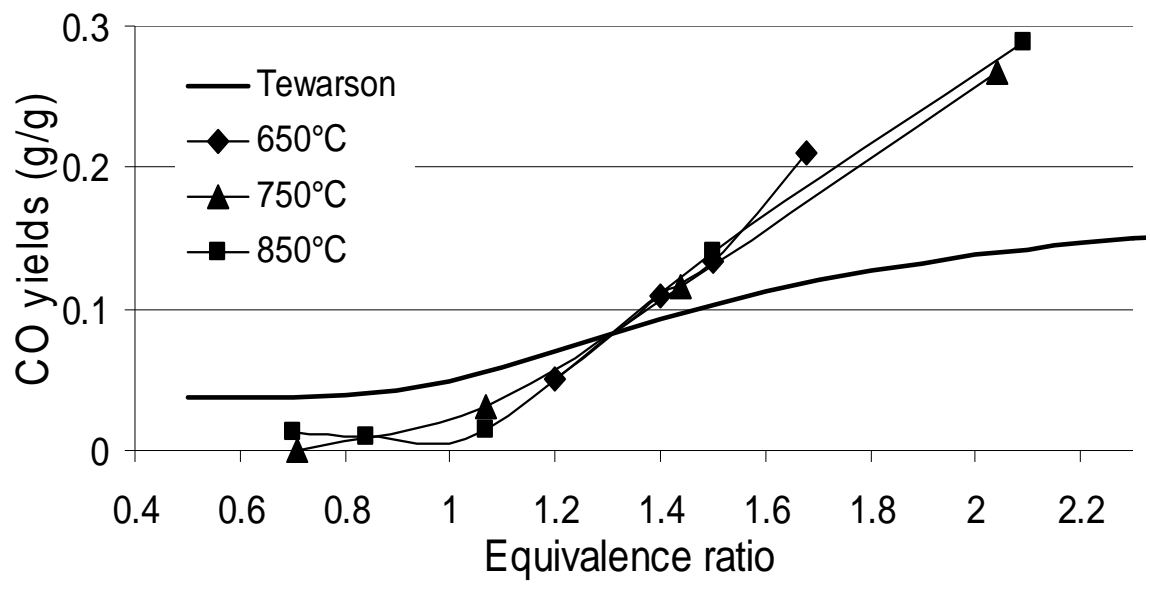

Figure 12 Nylon 6,6 carbon monoxide yields

Experiments carried out at each temperature give relatively low carbon monoxide yields at well ventilated conditions $(\phi<0.85)$. As the fire develops, the carbon monoxide yield increases as the equivalence ratio increases. The relationship between $\mathrm{CO}$ yield and equivalence ratio is independent of furnace temperature. A similar relationship is observed for hydrocarbons and hydrogen cyanide. Hydrocarbon and HCN yields, presented in Figure 13 and Figure 14, increase with the increase of equivalence ratio and neither depends on the furnace temperature. The Tewarson predictions show smaller change in carbon monoxide yields and from well-ventilated to under-ventilated slightly larger hydrocarbon yields than found in the steady state tube furnace. 


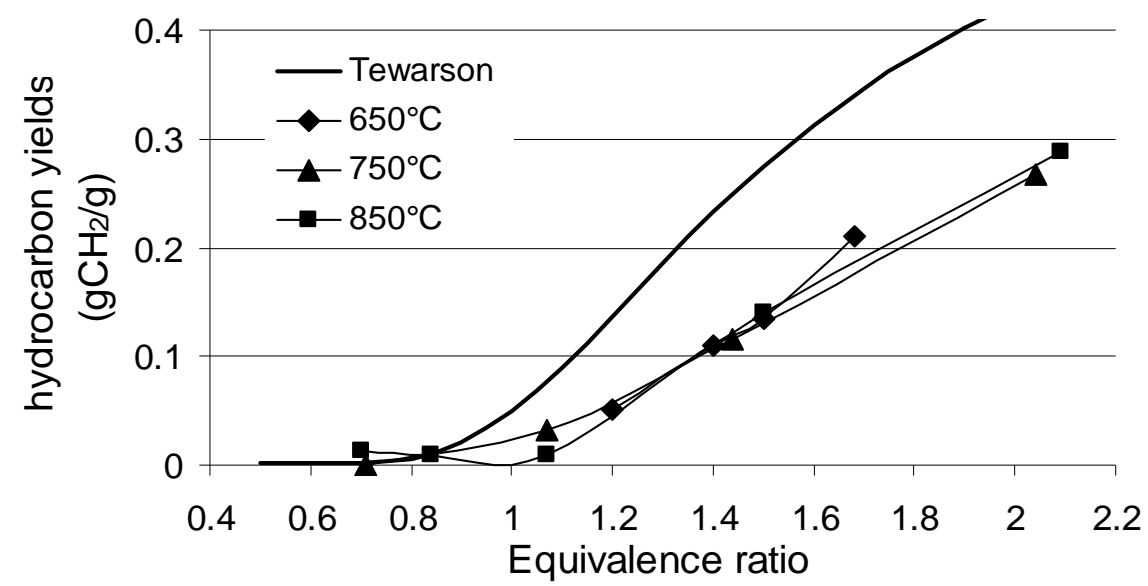

Figure 13 Nylon 6.6 hydrocarbon yields

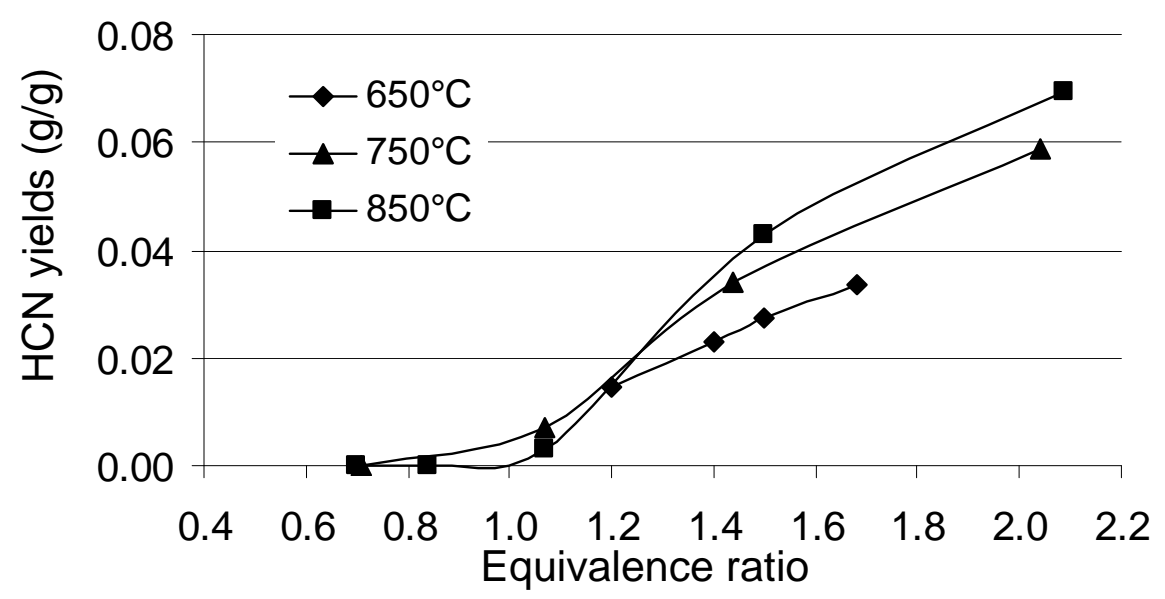

Figure 14 Nylon 6.6 HCN yields

In summary, yields obtained from burning different materials have been shown to be highly dependent upon the fuel/oxygen ratio (equivalence ratio) as well as the nature of the material. It is therefore vital that in any standard method for determination of toxic product yields, the relationship of product yields to the range of variables affecting the decomposition conditions is established. Given the very large variation reported in the literature of fire toxicity data, the good agreement with the Tewarson predictions is very welcome. It is interesting to note that apart from 
Polystyrene where the data set is too limited for a fair comparison, Tewarson consistently predicts higher hydrocarbon yields and in two cases out of three higher CO yields.

\section{CONCLUSIONS}

The yields of most species for most of the polymers studied are independent of the tube furnace temperature over the range studied $650-850^{\circ} \mathrm{C}$. The LDPE, PS and Nylon 6.6 results clearly show similarities in behaviour for yields of CO, HCN and hydrocarbons at the different temperatures studied. A different behaviour pattern is observed for PVC. As stated above, the toxic product yields for PVC appear to be almost independent of the fire conditions, equivalence ratio, and temperature.

The prediction reported by Tewarson obtained in fire propagation apparatus generally correspond well with steady state tube furnace data, particularly showing similar trends with ventilation condition, but tending to predict slightly higher hydrocarbon yields. Poor agreement with PVC CO yield under well-ventilated conditions is believed to be due to differences in the sample decomposition history, and the method by which $\phi$ is determined.

\section{REFERENCES}

${ }^{1}$ S.L.Madorsky Thermal degradation of organic polymers, Interscience Publishers, A Division of John Wiley \& Sons Inc, 1964

${ }^{2}$ G.Hartzell Toxicology, Vol. 115, p.7-13, 1993

${ }^{3}$ BS 7990:2003 Tube Furnace method for the determination of toxic product yields in fire effluents

4 A. Tewarson, SFPE Handbook of Fire Protection Engineering, National Fire Protection Association, Third Edition, p.3.82-3.161, 2002 
${ }^{5}$ D.A. Purser, (2002) ASET and RSET: addressing some issues in relation to occupant behaviour and tenability. $7^{\text {th }}$ International Symposium On Fire Safety Science, Worcester Polytechnic Institute - Worcester Massachusettes, USA 16 - 21 June 2002. Fire Safety Science - Proceedings of the seventh international symposium. International Association for Fire Safety Science, p. 91-102, 2003

6 T.R. Hull, K. Lebek, and K.T. Paul, Proceedings of the 8th International Symposium on Fire Safety Science, p1059-1070, 2005

7 ISO 19703:2005 Generation and analysis of toxic gases in fire -- Calculation of species yields, equivalence ratios and combustion efficiency in experimental fires

${ }^{8}$ P. Blomqvist, and A. Lonnermark, Fire and Materials, Vol. 25, p.71-81, 2001

${ }^{9}$ ISO TS 19700:2006 Controlled equivalence ratio method for the determination of hazardous components of fire effluents

10 T.R. Hull, J.M. Carman, D.A. Purser, Polymer International, Vol. 49, p.1259-1265, 2000

11 T.R. Hull, K Lebek, A A Stec, K T Paul, and D Price, Advances in the Flame Retardancy of Polymeric Materials: Current perspectives presented at FRPM'05 Ed. B. Schartel, Berlin, 2007 (in press).

12 A.Tewarson, F.H.Jiang and T.Morikawa, Ventilation-Controlled Combustion of Polymers, Combustion and Flame, Vol. 95, p.151-169, 1993

${ }^{13}$ W.M. Pitts, Progress in Energy and Combustion Science, Vol. 21, p.197-237,1995

14 K. Lebek, T.R. Hull, D. Price, Fire and Polymers: Materials and Concepts For Hazard Prevention, ACS Symposium Series No.922, Oxford University Press, p.344, 2005

15 T.R. Hull, D. Purser, R.E. Quinn, I.G.Areri, Polymer Degradation and Stability, Vol. 77, p. 235-242, 2001 